\title{
Kymachrysa, a new genus of Nearctic Green Lacewings (Neuroptera, Chrysopidae, Chrysopini)
}

\author{
Catherine A. Tauber', J. Allan Garland ${ }^{2}$ \\ I Department of Entomology, Comstock Hall, Cornell University, Ithaca, NY 14853 and Department of \\ Entomology \& Nematology, University of California, Davis, CA 95616, U.S.A. 2 Department of Entomology, \\ Macdonald College of McGill University, Ste. Anne de Bellevue, Quebec, Canada H9X 3V9 and P. O. Box \\ 24143, Penticton, British Columbia V2A 8L9, Canada
}

Corresponding author: Catherine A. Tauber (cat6@cornell.edu)

Academic editor: A. Contreras-Ramos | Received 29 May 2014 | Accepted 7 August 2014 | Published 28 August 2014

http://zoobank.org/08D36F92-DFD1-438C-88A3-E77D0C2FF011

Citation: Tauber CA, Garland JA (2014) Kymachrysa, a new genus of Nearctic Green Lacewings (Neuroptera, Chrysopidae, Chrysopini). ZooKeys 437: 87-108. doi: 10.3897/zookeys.437.7984

\begin{abstract}
Two North American species of green lacewings have undergone a number of changes in their generic assignments and are currently classified as incertae sedis. Here we demonstrate that adults (both sexes) and larvae of these species share a set of features that distinguishes them from currently described genera. Thus, to promote nomenclatural stability in Chrysopidae, we describe Kymachrysa, a gen. n. that contains the two species - Kymachrysa intacta (Navás), comb. n. and Kymachrysa placita (Banks), comb. n.. Also, we present modifications for the current generic-level key, illustrations, as well as biological information for identifying the genus and its known species.
\end{abstract}

\section{Keywords}

New genus, adult, larva, biology

\section{Introduction}

The green lacewing tribe Chrysopini (Neuroptera: Chrysopidae) includes seventeen genera in the New World; ten of these occur in the Nearctic. These New World genera are distinguished from each other on the basis of both adult (male and female), as well as larval, characters (e.g., see Brooks and Barnard 1990; Tauber 1974, 1975, 2003; 
Adams and Garland 1982; Brooks 1994; Penny et al. 2000; Tauber and de Leon 2001; Tauber et al. 2000, 2014; Freitas and Penny 2001). However, the adult and larval characteristics of two Nearctic species were shown to be inconsistent with the genera to which the species had been assigned (Ceraeochrysa and Chrysopodes), nor could they be assigned to any other known chrysopine genus (Tauber and Flint 2010: 64). Most recently, they were retained temporarily in Ceraeochrysa (with the caveat of incertae sedis) (Tauber and Flint 2010: 64). Here, to foster nomenclatural stability, we describe a new genus to accommodate these two species (original names: Chrysopa placita Banks and Chrysopa intacta Navás), and we provide information for their identification.

\section{Specimens and methods}

Our procedures were those used in previous publications (e.g., Tauber et al 2012, Silva et al. 2013). We examined specimens from the following collections: BMNH, The Natural History Museum (formerly British Museum of Natural History), London, England; CAS, California Academy of Sciences, San Francisco, CA; CMNH, Carnegie Museum of Natural History, Pittsburgh, PA; CNC, Canadian National Collection, Ottawa, Canada; CPG, C. P. Gilette Museum of Arthropod Diversity, Colorado State University, Fort Collins, CO; CUIC, Cornell University Insect Collection, Ithaca, NY; EMEC, Essig Museum of Entomology, University of California, Berkeley, CA; MCZ, Museum of Comparative Zoology, Harvard University, Cambridge, MA; ROM, Royal Ontario Museum, Toronto, ON, Canada; SDNHM, San Diego Natural History Museum, San Diego, CA; TRC, M. J. \& C. A. Tauber Research Collection, Davis, CA; USNM, National Museum of Natural History (formerly United States National Museum), Smithsonian Institution, Washington, D.C.

\section{Systematics}

Genus Kymachrysa gen. n.

http://zoobank.org/56199711-0065-45BA-A035-414069FFA32D

Type-species. Chrysopa placita Banks, 1908: 259.

Distinguishing adult features. Kymachrysa adults appear to be typical chrysopine lacewings of medium size and green coloration. Their most distinctive adult features occur in the male and female terminalia; in addition, a few external features are diagnostic of the genus:

External features. (i) The longitudinal (radial) veins between the first and second rows of gradate veins of the fore and hind wings are sinuous (Fig. 1A, B), whereas in most other chrysopid genera they are relatively straight. (ii) In both males and females, the fused ninth tergite and ectoproct is completely divided by a dorsal invagination, and each 


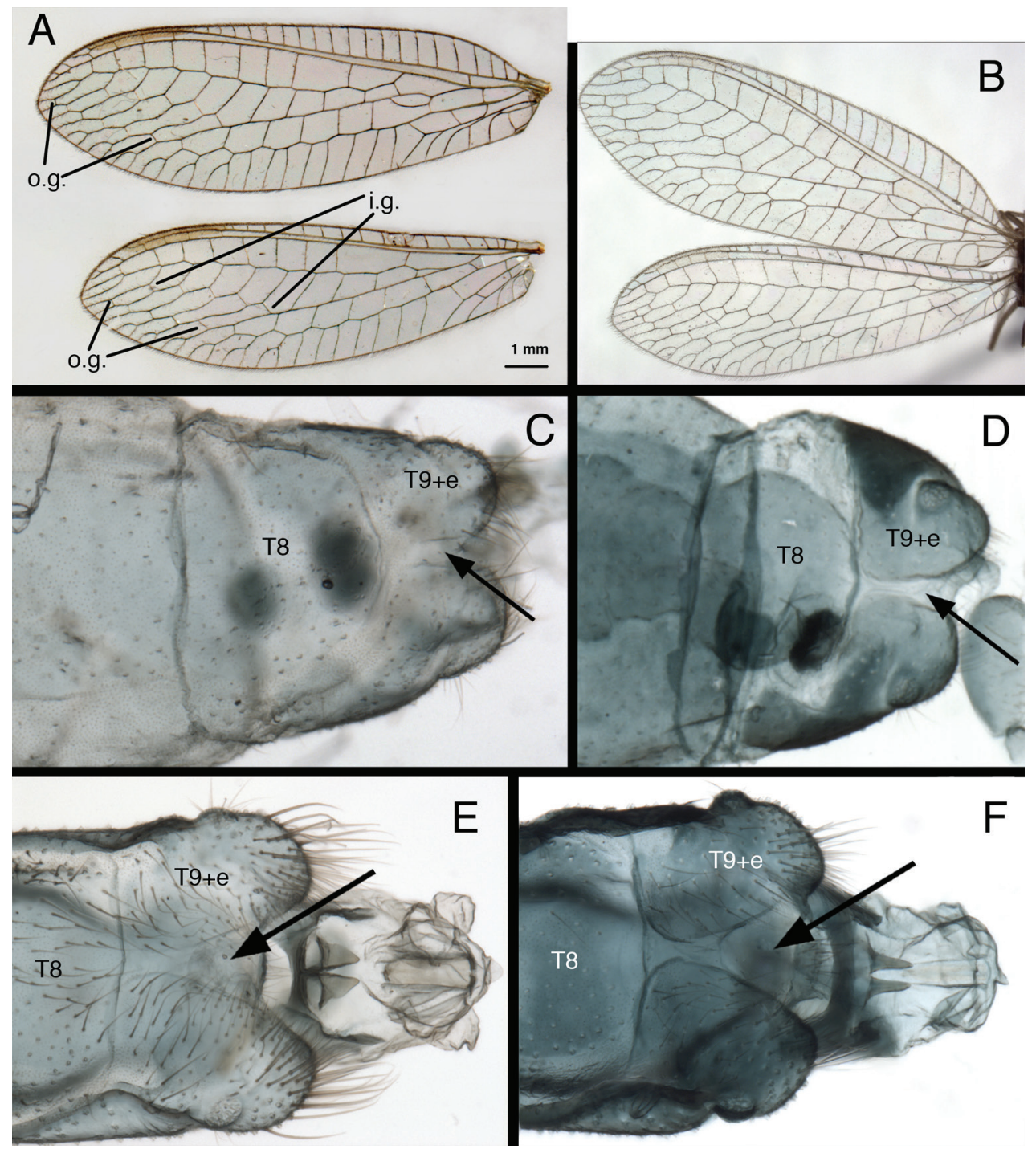

Figure I. Two external features that characterize Kymachrysa adults. A, B Fore and hind wings with sinuate longitudinal veins between the first and second gradate series of crossveins $\mathbf{C}-\mathbf{F}$ Terminal segments (dorsal) with Tergite 9+ectoproct separated dorsally C, D Female E, F Male A, C, E. K. placita A, C Colorado, USNM E Type, Colorado, MCZ B, D, F K. intacta B Neotype, Quebec, CNC D New York, TRC F New York, TRC [Males: gonarcal complex not removed]. Abbreviations: i.g. inner gradate veins o.g. outer gradate veins T8 eighth tergite T9+e fused ninth tergite and ectoproct.

side of the terminal abdominal segment is rounded posterolaterally (especially in males) (Fig. 1C-F). Among other New World genera, a complete dorsal invagination of the T9+ect is reported only for Chrysopiella and Parachrysopiella (Brooks and Barnard 1990). 


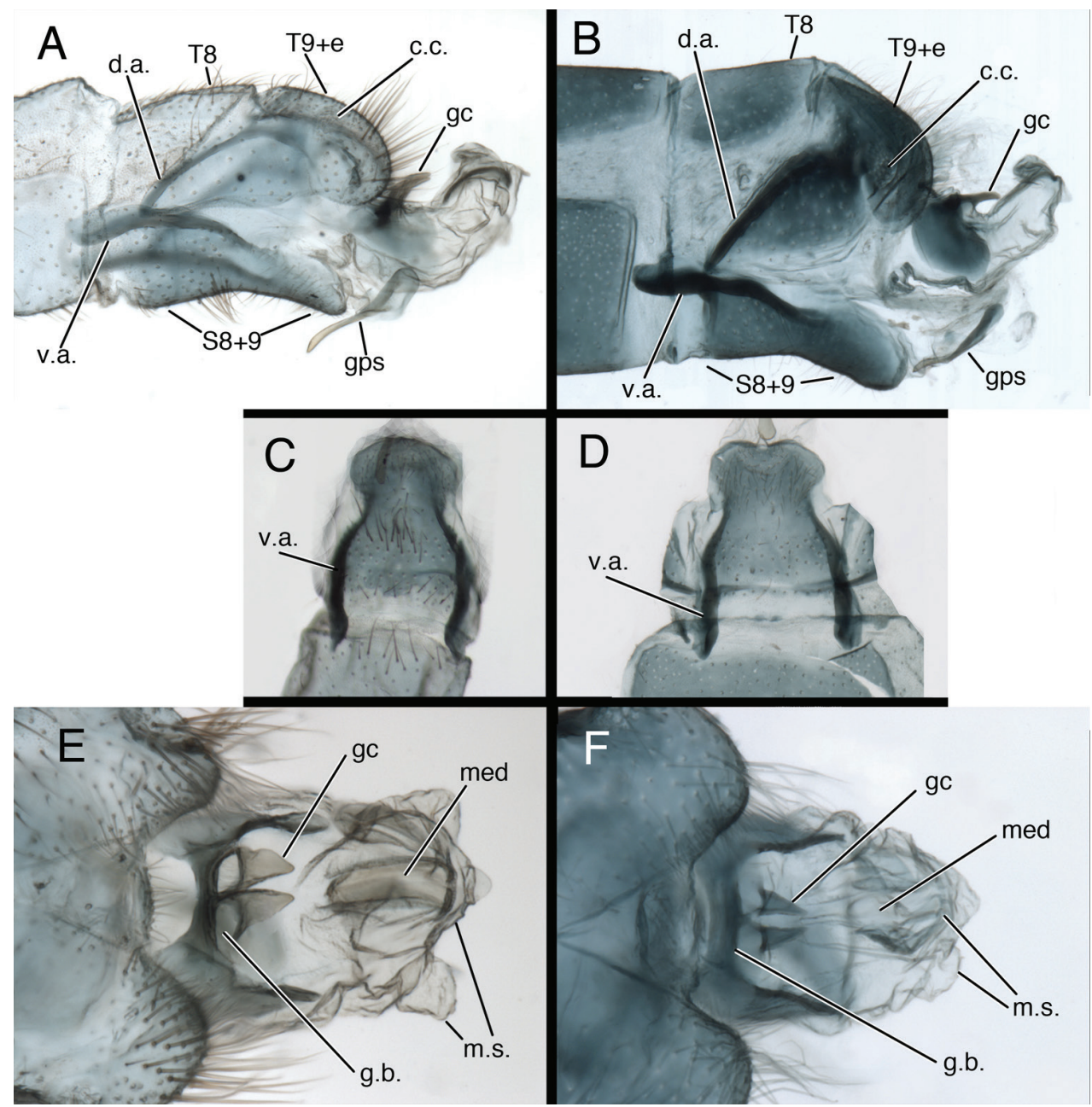

Figure 2. Kymachrysa male terminalia. A, B Abdominal segments 8 and 9 (lateral), with genitalia everted C, D Sternite $8+9$ (ventral) E, F Genitalia (everted, dorsal) A, C, E $K$. placita Type, Colorado, MCZ B, D, F K. intacta, California, TRC. Abbreviations: c.c. callus cerci d.a. dorsal apodeme (on ninth tergite and ectoproct) gc gonocornu gps gonapsis g.b. gonarcal bridge med mediuncus m.s. membranous sac S8+9 fused eighth and ninth sternites T8 eighth tergite T9+e fused ninth tergite and ectoproct v.a. ventral apodeme (on sternite 8+9).

Male terminalia. One of the most striking aspects of the Kymachrysa male terminalia is the $\mathbf{S} 8+9$, which is entirely fused and well sclerotized as in most chrysopine genera. However, in lateral view, the Kymachrysa S8+9 has an unusual ventral bend, and the ventral apodeme is heavy and elongate - extending anteriorly well beyond the proximal margin of S8 (Fig. 2A, B). In ventral view, $\mathrm{S} 8+9$ is constricted mesally and rounded both anteriorly and posteriorly (Fig. 2C, D). These features are unique among New World chrysopids. 
Gonocornua are present on the gonarcal bridge, as in Ceraeochrysa. In Ceraeochry$s a$, the gonocornua are usually rounded and unarticulated, and they arise laterally from the gonarcal bridge (see Freitas et al. 2009). But, the gonocornua of Kymachrysa are unusual in that they appear at least partially articulated or separated from the gonarcal bridge, and at the base they are juxtaposed and located mesally on the distal margin of the gonarcal bridge (Fig. 2E, F). Furthermore, the dorsum of the mediuncus has a distinct, trough-like shape not found in other genera; the terminus has a weak, lightly sclerotized or membranous beak mesally and expanded membranous sacs laterally.

Female terminalia. Two notable features distinguish the female genitalia. (i) This chrysopid genus is the only one outside of the tribe Belonopterygini (see Tjeder 1966: $235,324,337)$ in which the female is reported to have a praegenitale. [Note: the recording of a praegenitale for Leucochrysa (data matrix of Brooks and Barnard 1990: Table 1) appears to be an error - the description of the genus, p. 248, states that the structure is absent.] Moreover, the structure appears unique among chrysopids, in that it is asymmetrical (a condition not reported for Belonopterygini) (Fig. 3C, D). (ii) The spermatheca is shaped like a pillbox with a shallow invagination and a sail-shaped velum that opens via a slit to the bursal duct (Fig. 3F-H). By comparison, in Ceraeochrysa the spermatheca is cylindrical, with an elongate invagination and a U-shaped or J-shaped bend that opens via a slit directly to the bursa copulatrix (e.g., Adams and Penny 1985, Freitas and Penny 2001, Sosa and Freitas 2010, 2012). And, in Chrysopodes the spermatheca is cylindrical or tubular, with a very deep invagination and an elongate bursal duct (e.g., Adams and Penny 1985, Freitas and Penny 2001, Tauber 2010, Tauber et al. 2012). (iii) Finally, the Kymachrysa spermathecal duct (mature specimens) is hairy for almost its entire length; the terminal bristles are long and fine, and their length decreases proximally; at the base of the duct the bristles are very short and stubby, or granular in appearance (Fig. 3E, F).

Description. Adult (Figs 4, 5, 8C, D). Delicate, slender, medium sized (forewing length, $K$. placita: $11-13 \mathrm{~mm}$; $K$. intacta $11-15 \mathrm{~mm}$ ), predominantly green with yellow longitudinal stripe, mesally. Head (Figs 4, 5). Vertex with pair of crescent-shaped, red or brown sublateral marks (sometimes absent or faint), usually with lateral red or brown stripe near margin of eye; frons with or without markings; gena with red or brown longitudinal markings. Distal segments of labial, maxillary palpi with elongate, lateral, black marks. Antenna cream colored, without markings. Thorax (Figs 4E-H, 5F-J, 8C, D). Prothorax variable in length and shape (probably developmental variation), usually long, tapered distally; dorsum without lateral stripes, but usually with irregular, red or brownish, sublateral markings (especially western, southern specimens); mesothorax, metathorax with or without markings. Legs mostly light green, without markings, with numerous dark brown to black setae; tarsal claws with deep U-shaped to V-shaped cleft.

Wings (Fig. 1A, B) with costal area slightly enlarged basally; radius straight; im3 cell triangular; forewing, hindwing with two, regular, slightly converging rows of gradate veins; longitudinal veins between inner and outer gradates sinuate; three icu cells, distal one open.

Abdomen (Figs 1C-F, 2A, B, 3A, B, 6A, 7A, 8A, B) with spiracles simple; callus cerci round, located dorsally on $\mathrm{T} 9+\mathrm{ect}$, with trichobothria stemming from closely 


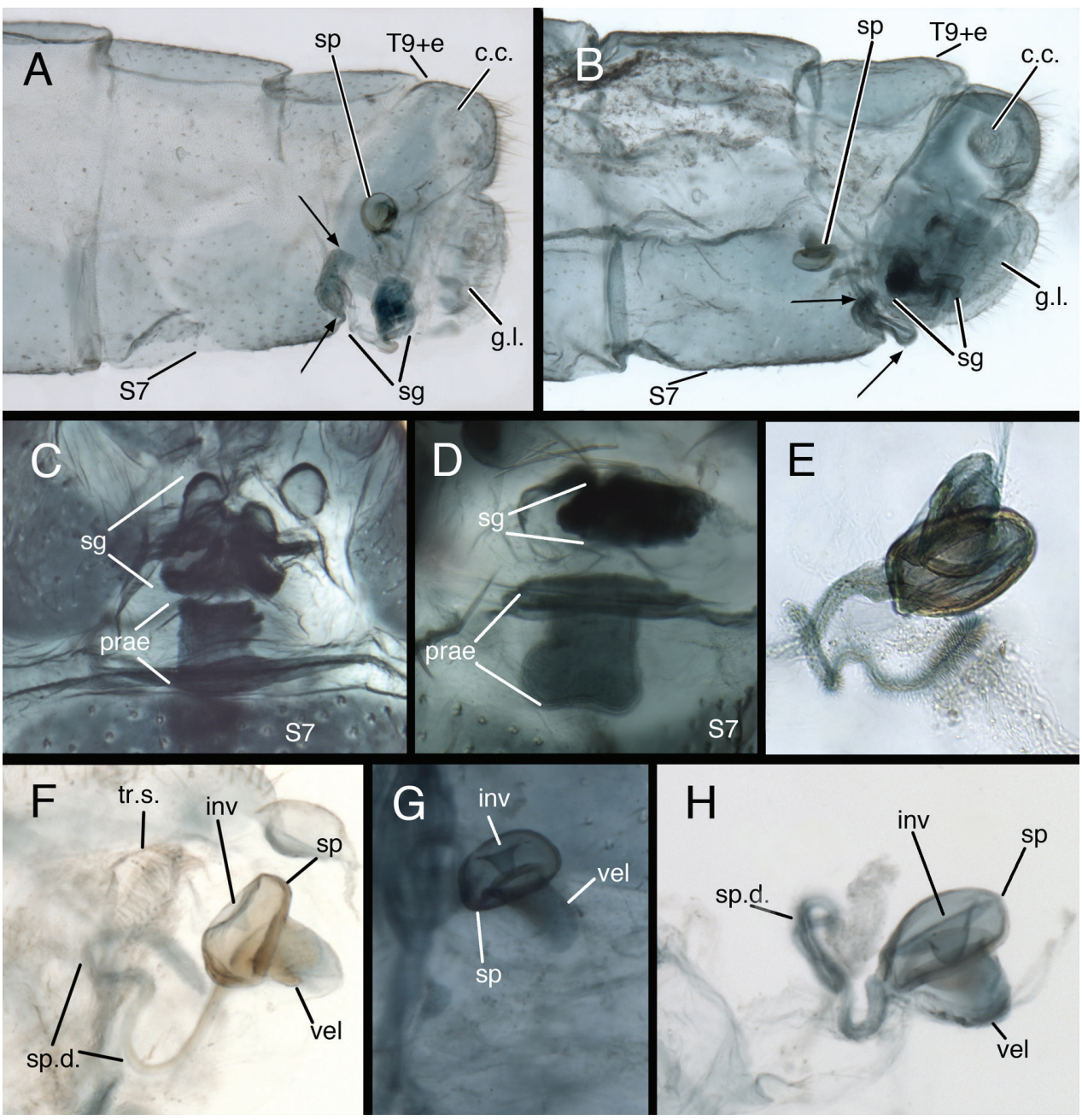

Figure 3. Kymachrysa female terminalia. A, B Abdominal segments 7 and 9 (lateral) [Arrows delineate the praegenitale] C, D Praegenitale at distal margin of S7 (ventral) E-H Spermatheca A, C, F $K$. placita A, F Colorado, USNM C New Mexico, USNM B, D, E, G, H $K$. intacta B, D, E New York, TRC G Colorado, CPG H California, TRC. Abbreviations: c.c. callus cerci g.l. gonapophysis lateralis inv spermathecal invagination prae praegenitale sg subgenitale sp spermatheca sp.d. spermathecal duct S7 seventh sternite tr.s. transverse sclerite T9+e fused ninth tergite and ectoproct vel velum.

spaced sockets; ninth tergite (T9) and ectoproct fused, forming T9+ect; T9+ect completely divided dorsally.

Male abdomen (Figs 2, 6-8) slender, with sternites tall $(-0.7 \times$ length), with or without microtholi; spiracles simple; terminal segments (A8-A9) compact; ectoproct with heavy apodeme along entire dorsal margin, terminus reaching proximal edge of eighth sternite (S8); eighth and ninth sternites fused; $58+9$ shallow, with dorsal surface undulating, anterior section of $S 8+9$ with heavy ventral apodeme extending 


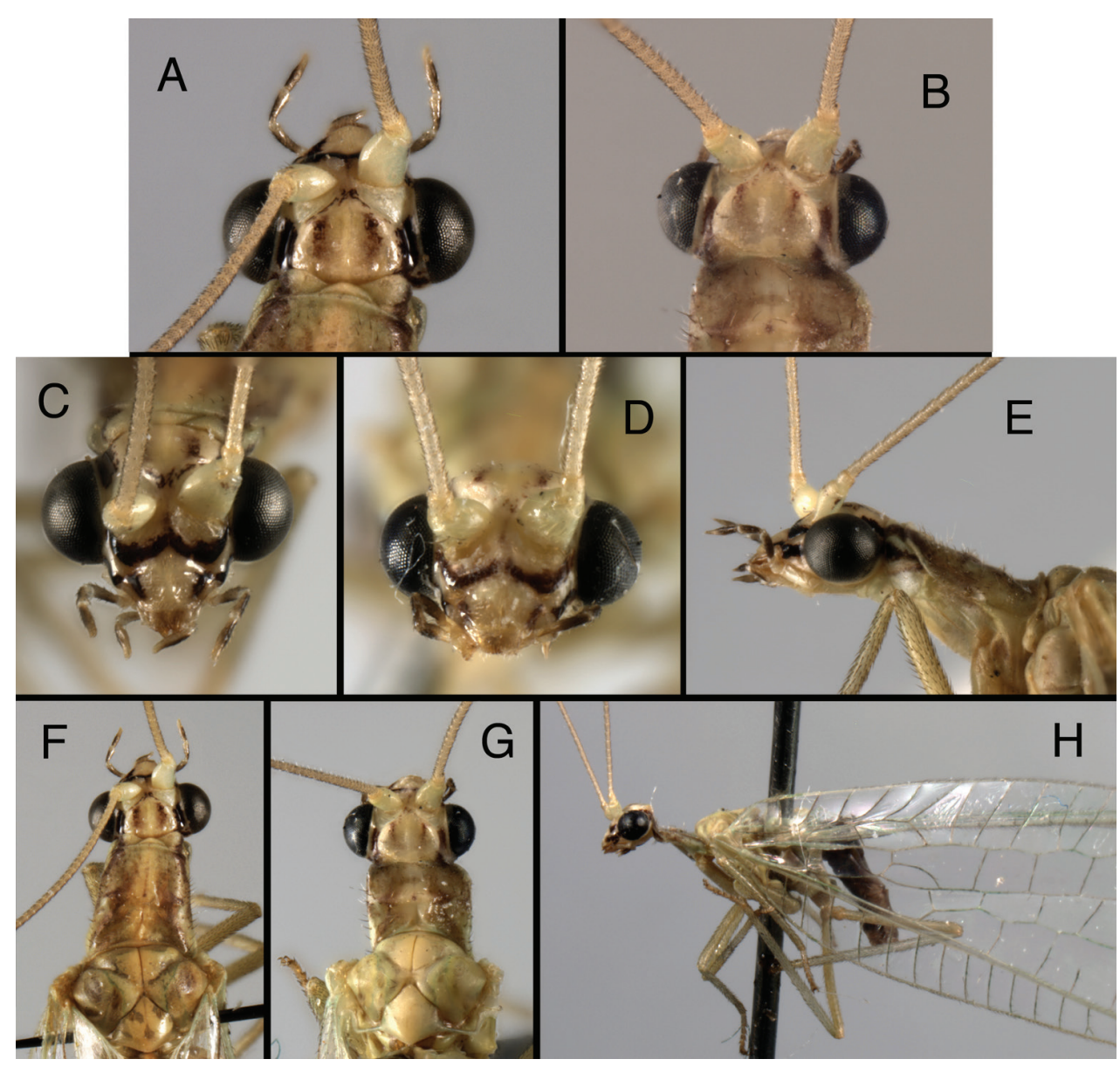

Figure 4. Kymachrysa placita external adult features. Note variation in darkness and size of head markings, prothoracic size and shape. A, B Head (dorsal) C, D Head (frontal) E Head, prothorax (lateral) F, G Head, prothorax, mesothorax (dorsal) $\mathbf{H}$ Head, thorax (lateral) [Background with small piece of abdomen visible]. A, C, E, F Wyoming, SDNHM; B, D, G, H Colorado, CPG.

proximally well beyond margin of segment, into S7; ventral surface indented mesally (hour-glass shaped). Gonapsis, hypandrium internum attached to membrane at tip of S9; gonapsis elongate, with basal margin rounded, toothed, distal margin expanded, curved; gonocristae absent. Gonarcus arcuate, with stout bridge, rounded, expanded lateral apodemes; gonocornua triangular, articulated on laterodistal margin of gonarcal bridge; base of gonocornua clear, tip dark, heavy, tapering to angulate terminus; entoprocessus absent. Mediuncus weak, comprising very lightly sclerotized, curved, mesal band distal to gonocornua, with trough-shaped dorsal surface, small, rounded, membranous terminus. Gonosaccus large, expanded dorsally as pair of large, eversible, distal sacs, expanded ventrally with a second pair of large, eversible sacs; gonosetae absent. 


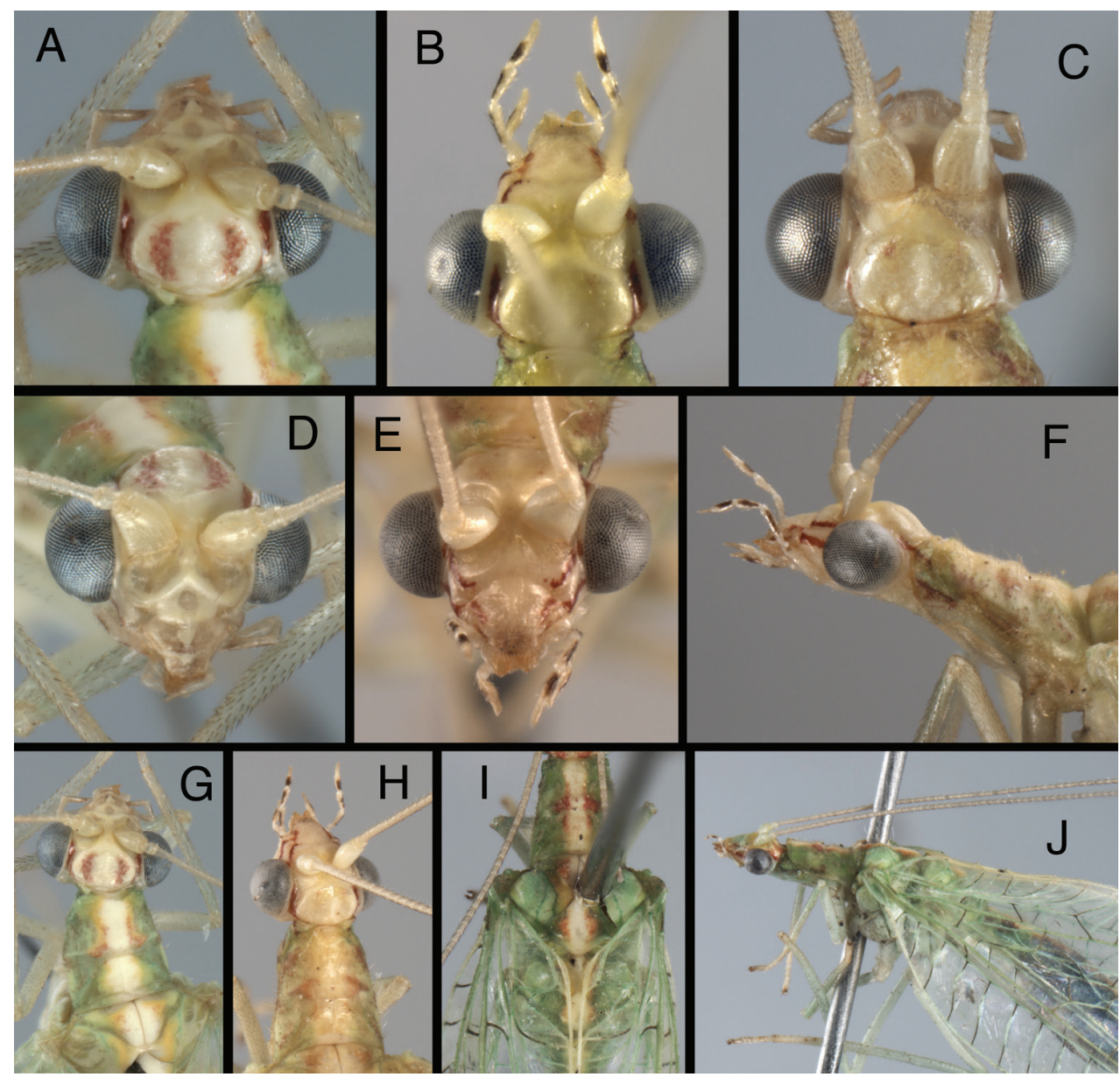

Figure 5. Kymachrysa intacta external adult features. Note variation in the presence, darkness, and size of head and thoracic markings. A-C Head (dorsal) D, E Head (frontal) F Head, prothorax (lateral) G, H Head, prothorax, mesothorax (dorsal) I Thorax (dorsal) J Head, thorax (lateral) A, D, G, I, J California, TRC B, E, F, H Colorado, TRC; C New York, TRC.

Female abdomen (Fig. 3) robust, not slender; terminalia compact. Praegenitale present, extending as truncated lobe from distal margin of S7, with distal, asymmetrical lobe, comb-shaped, with single long seta; lobe extending distally beyond S7 or curving internally. Colleterial gland, reservoir membranous, very delicate, extending proximally well into A7; transverse sclerite relatively large, broad, comb-shaped, with elongate teeth. Spermathecal complex simple; spermatheca small, pillbox shaped with small to moderate, U-shaped invagination, sail-like velum, opening to bursa copulatrix via elongate slit and small, membranous bursal duct; spermathecal duct elongate $(>3 \times$ width of spermatheca), curvy, covered with fine hairs throughout (mature specimens), most dense, long distally, becoming short, stubby basally; immature specimens with basal $-10-20 \%$ of spermathecal duct smooth. Bursa copulatrix small, delicate, membranous, sac-like; 


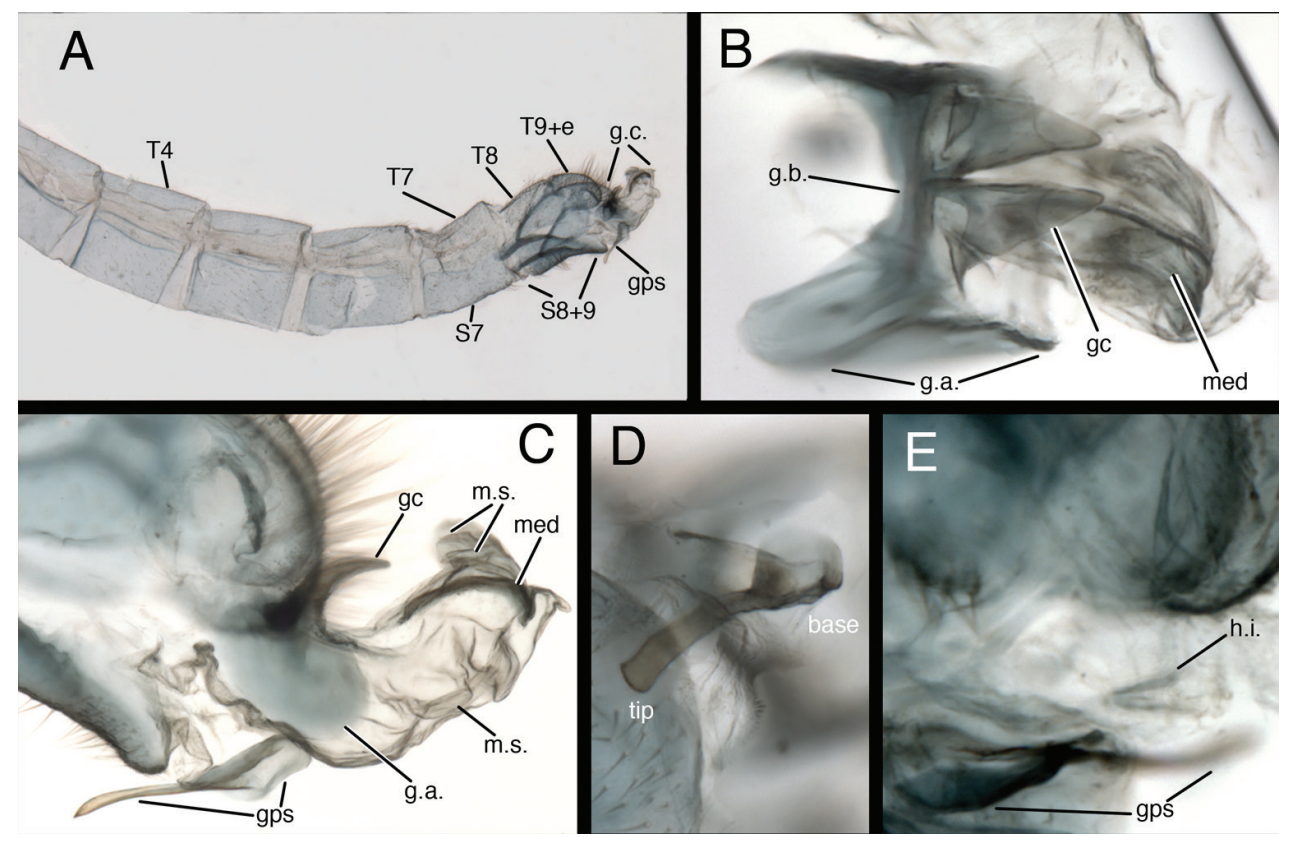

Figure 6. Kymachrysa placita male abdomen. A Abdominal segments 3 to terminus (lateral), with genitalia everted B Gonarcal complex (dorsal) C Genitalia (everted-including gonapsis, lateral) D Gonapsis (ventral) E Hypandrium internum nestled within membrane [Gonapsis not in focus, shown for relative scale]. All Types, Colorado, MCZ Abbreviations: gc gonocornu gps gonapsis g.a. gonarcal apodeme g.b. gonarcal bridge g.c. gonarcal complex h.i. V-shaped hypandrium internum med mediuncus m.s. membranous sac $\mathbf{S} 7$ seventh sternite S8+9 fused eighth and ninth sternites $\mathbf{T} \mathbf{x}$ tergite, number $\mathbf{T 9 + e}$ fused ninth tergite and ectoproct.

bursal glands either absent or very small. Subgenitale large, robust, triangular in ventral view, with pair of distal lobes, extending outward or concealed beneath ectoprocts.

Etymology. The prefix "Kyma-" comes from the Greek word kýma (xíua), meaning wave, and refers to the wavy, or sinuate, longitudinal veins between the gradate veins of the forewings that distinguish the two species currently assigned to the genus. The suffix follows the traditional series of chrysopid names ending in "-chrysa" - Greek, feminine, " $\chi \varrho \cup \sigma \alpha$ ” meaning golden.

Geographic distribution. The genus, which currently includes only two species, appears to be restricted to North America (Canada, United States and Mexico, as far south as Mexico City) (Adams 1982, Penny et al. 1997, Tauber 2003, Valencia Luna et al. 2006, Garland and Kevan 2007, Freitas et al. 2009, Tauber and Flint 2010, all as Ceraeochrysa or Chrysopodes).

Characteristics of Kymachrysa larvae. The larvae of only one of the Kymachrysa species (K. intacta) were described (Tauber et al. 1998, as Ceraeochrysa placita). Later they were shown to share a large number of distinctive characteristics with the larvae of several species of Chrysopodes, and as a result the species was transferred to Chrysopodes (Tauber 2003, as C. placita). 


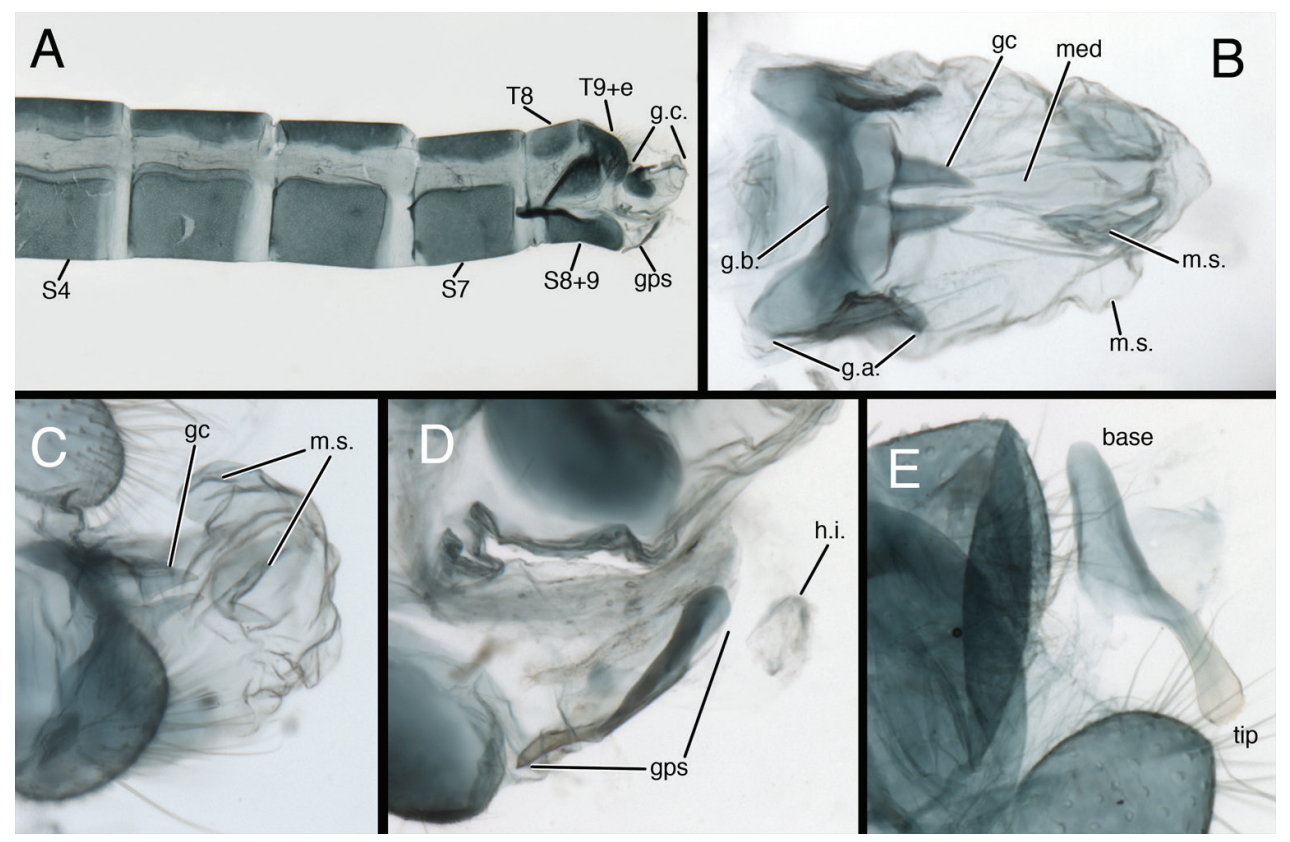

Figure 7. Kymachrysa intacta male abdomen. A Abdominal segments 4 to terminus (lateral), with genitalia everted B Gonarcal complex (dorsal) C Everted genitalia (dorsolateral), showing dorsal membranous sacs D Gonapsis (lateral), hypandrium internum (dorsal) E Gonapsis (ventral). A, D California, TRC B, E New York, TRC; C Colorado, CPG. Abbreviations: gc gonocornu gps gonapsis g.a. gonarcal apodeme g.b. gonarcal bridge g.c. gonarcal complex h.i. V-shaped hypandrium internum med mediuncus $\mathbf{m} . \mathbf{s}$. membranous sac $\mathbf{S} \mathbf{x}$ sternite, number $\mathbf{S 8 + 9}$ fused eighth and ninth sternites $\mathbf{T} 8$ eighth tergite T9+e fused ninth tergite and ectoproct.

Recently, larvae from additional species of Chrysopodes were described in sufficient detail for more robust comparisons than were possible earlier. Now, detailed larval descriptions are available for six of the 47 currently recognized species of Chrysopodes [Tauber 2003: Chrysopodes (Neosuarius) collaris (Schneider); Silva et al. 2013: Chrysopodes (Chrysopodes) divisus (Walker), Chrysopodes (C.) fumosus Tauber \& Albuquerque, Chrysopodes (C.) geayi (Navás), Chrysopodes (C.) linaefrons Adams \& Penny; Chrysopodes (C.) spinellus Adams \& Penny]. Comparisons with these species confirm that $K$. intacta larvae differ only slightly from those of Chrysopodes. And, given the large percentage of species in both Kymachrysa and Chrysopodes with undescribed larvae, it is not clear at this time, which, if any, of these differences will be informative at the generic level.

Nevertheless, the following features appear most noteworthy:

(a) Setae: Previously, certain setae on the K. intacta Semaphorant B were reported to be "serrated" or "thorny", similar to those on Chrysopodes; these setae include the LS of the thorax and A4-A8, the large LDS on A6 and A7, and some dorsal thoracic setae ("serrated": Tauber et al. 2000, as Ceraeochrysa placita; "thorny": 


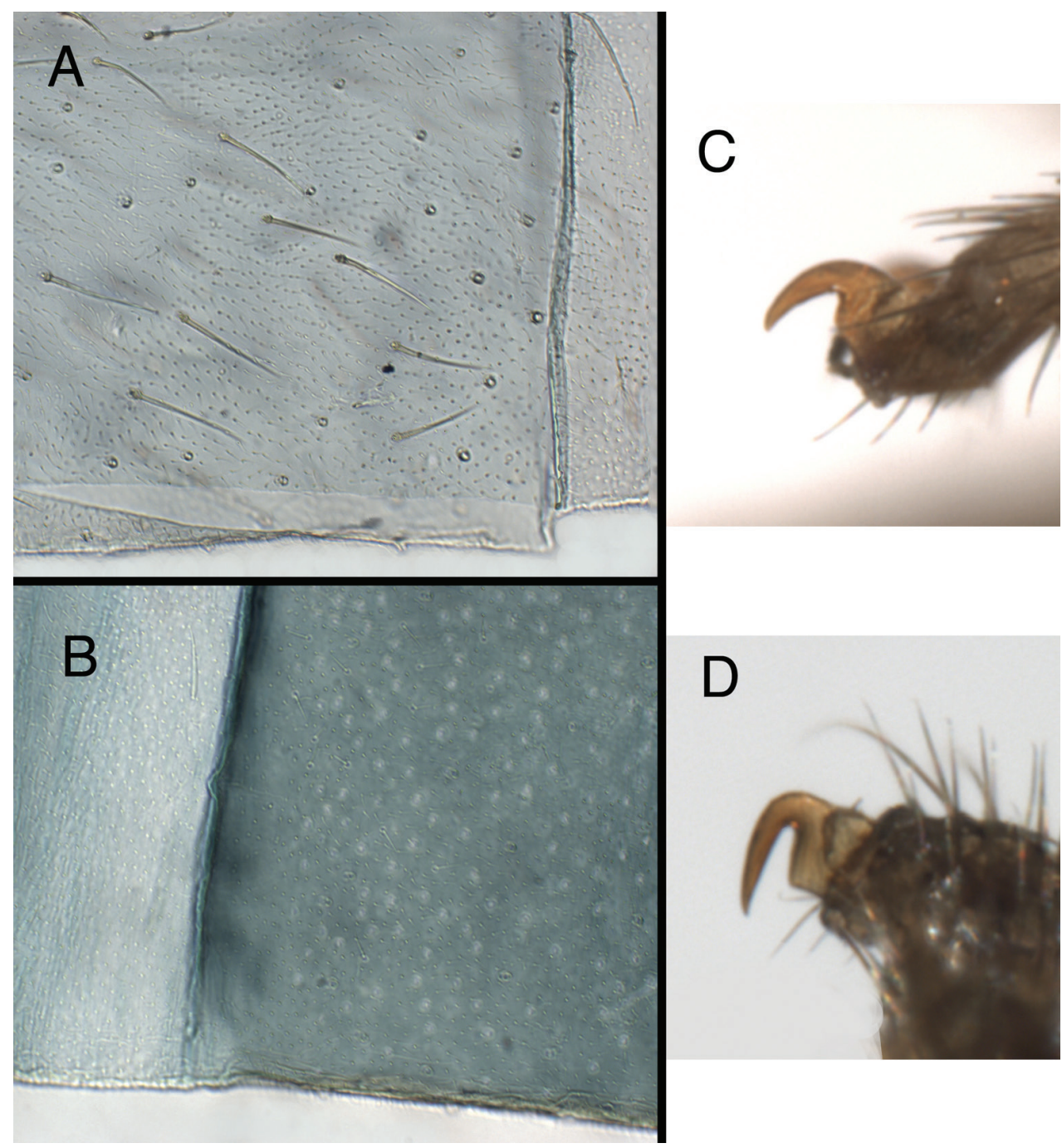

Figure 8. A, B Integument of fifth abdominal sternite. A $K$. placita, without microtholi [typical of $K$. placita and some $K$. intacta populations (see text)] B $K$. intacta, with microtholi (typical of some populations). C, D Prothoracic tarsal claw. C $K$. placita D $K$. intacta. A Type, Colorado, MCZ; B California, TRC; C Wyoming, SDNHM; D Minnesota, CMNH.

Tauber 2003, as Chrysopodes placita). Subsequent comparison of these setae with those of the six described Chrysopodes species (under higher magnification) indicates that the setal surface of $K$. intacta (Semaphorant B) falls outside the range of variation exhibited by Chrysopodes (Chrysopodes) and Chrysopodes (Neosuarius). Rather than serrated or thorny, the K. intacta setae have a more sabulose (sandy) or granular surface (Fig. 9C-F). [Note: the same setae on Semaphorant A are thorny on both Chrysopodes and $K$. intacta.] 
(b) Metathoracic fold: One of the primary reasons for transferring K. intacta to Chrysopodes (Tauber 2003, as C. placita) was the shared characteristic of an unusual posterior fold on the larval metathorax. In both taxa, the fold rises well above the anterior part of the metathorax, and it bears a transverse row (R1) of robust setae that stem from enlarged chalazae and that are usually slightly longer than the submedian setae (SMS) on abdominal segments A1 through A6. However, subsequent comparisons indicated that aspects of this feature present some small, but significant differences between $K$. intacta and Chrysopodes.

First, as discussed above, the surface of the R1 setae on K. intacta Semaphorant B is distinctive. It is sabulose (sandy), not thorny as in Chrysopodes.

Second, although the body dimensions of the L3 larvae of Chrysopodes (Chrysopodes) and $K$. intacta that we studied are similar, the length, robustness, and stiffness of the setae differ between the two taxa (Table 1, Fig. 9). For example, in Chrysopodes (Chrysopodes), the $\mathrm{R} 1$ setae range in length between $0.28-0.42 \mathrm{~mm}$, and they are thick and erect throughout their entire lengths. In comparison, the $K$. intacta $\mathrm{R} 1$ setae range between $0.48-0.62 \mathrm{~mm}$; they are slender throughout, and only the basal section stands erect - the distal section tends to curve. [Note: In the large bodied Chrysopodes (Neosuarius) collaris (Schneider), both the R1 setae and SMS are slightly longer and more slender and flexible than those of Chrysopodes (Chrysopodes) species (Table 1).]

Third, the larvae of Chrysopodes spp. (all instars, including the first) have dark brown markings on the frontal surface of the chalazae in metathoracic R1; these markings are elliptical to ovate and at least as broad as the setal base. In K. intacta (second and third instars) they are light brown in color, elongate, and narrower than the setal base (Fig. 9A, B); they are either absent or very light in first instars.

Biological features of Kymachrysa. Adult specimens of K. placita are not common; those that we have seen were collected during July and August. No larval specimens are reported. $K$. intacta appears to be more abundant; we have seen adult specimens collected from June through mid-October (mostly August), and we have collected larvae during March and April (overwintering second instars) and in September and October (prehibernal first instars).

Biological features have been investigated only for K. intacta (Tauber et al. 1998). In populations from both eastern and western USA (NY and CA), eggs are laid and larvae occur on the trunks of medium-sized to large-sized deciduous and evergreen

Table I. Larval setal lengths (range): comparison between Kymachrysa intacta and Chrysopodes species.

\begin{tabular}{c|c|c}
\hline Species & T3-R1 & SMS \\
\hline Kymachrysa intacta & $0.48-0.62 \mathrm{~mm}$ & $0.28-0.43 \mathrm{~mm}$ \\
\hline Chrysopodes (Chrysopodes) divisus & $0.28-0.36 \mathrm{~mm}$ & $0.24-0.36 \mathrm{~mm}$ \\
\hline Chrysopodes (Chrysopodes) geayi & $0.39-0.42 \mathrm{~mm}$ & $0.21-0.36 \mathrm{~mm}$ \\
\hline Chrysopodes (Neosuarius) collaris & $0.43-0.51 \mathrm{~mm}$ & $0.31-0.47 \mathrm{~mm}$ \\
\hline
\end{tabular}




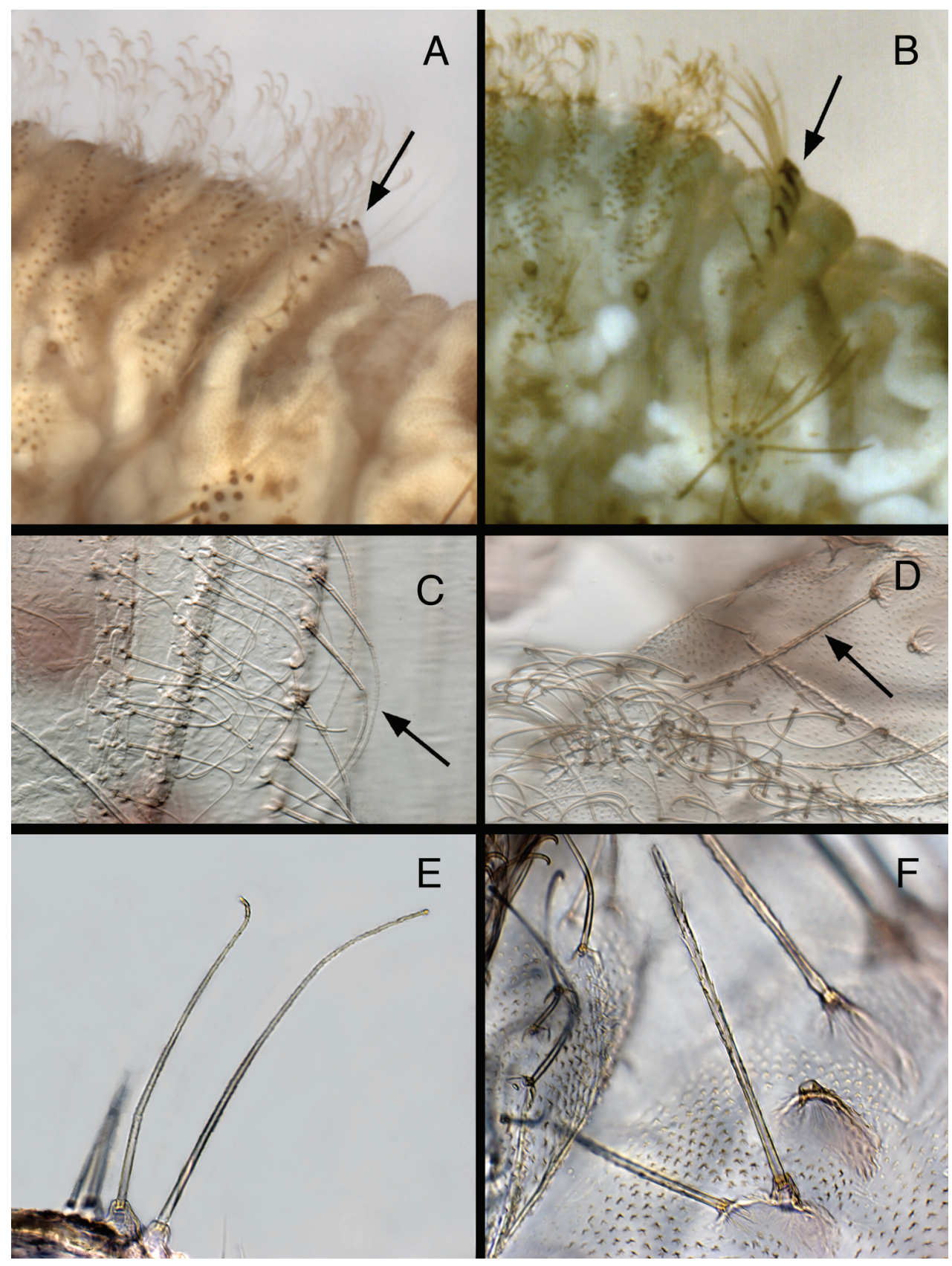

Figure 9. Larval characteristics that distinguish Kymachrysa from Chrysopodes. A, B Raised metathoracic posterior fold [Arrows indicate dark setal bases with distinctive anterior markings] C-F Setae on raised metathoracic fold [Note slender, curved structure, granular surface (Kymachrysa) vs robust, erect structure, thorny surface (Chrysopodes)] A, C, E K. intacta (Californa, TRC) B, D, F Chrysopodes geayi (Rio de Janeiro, TRC). 


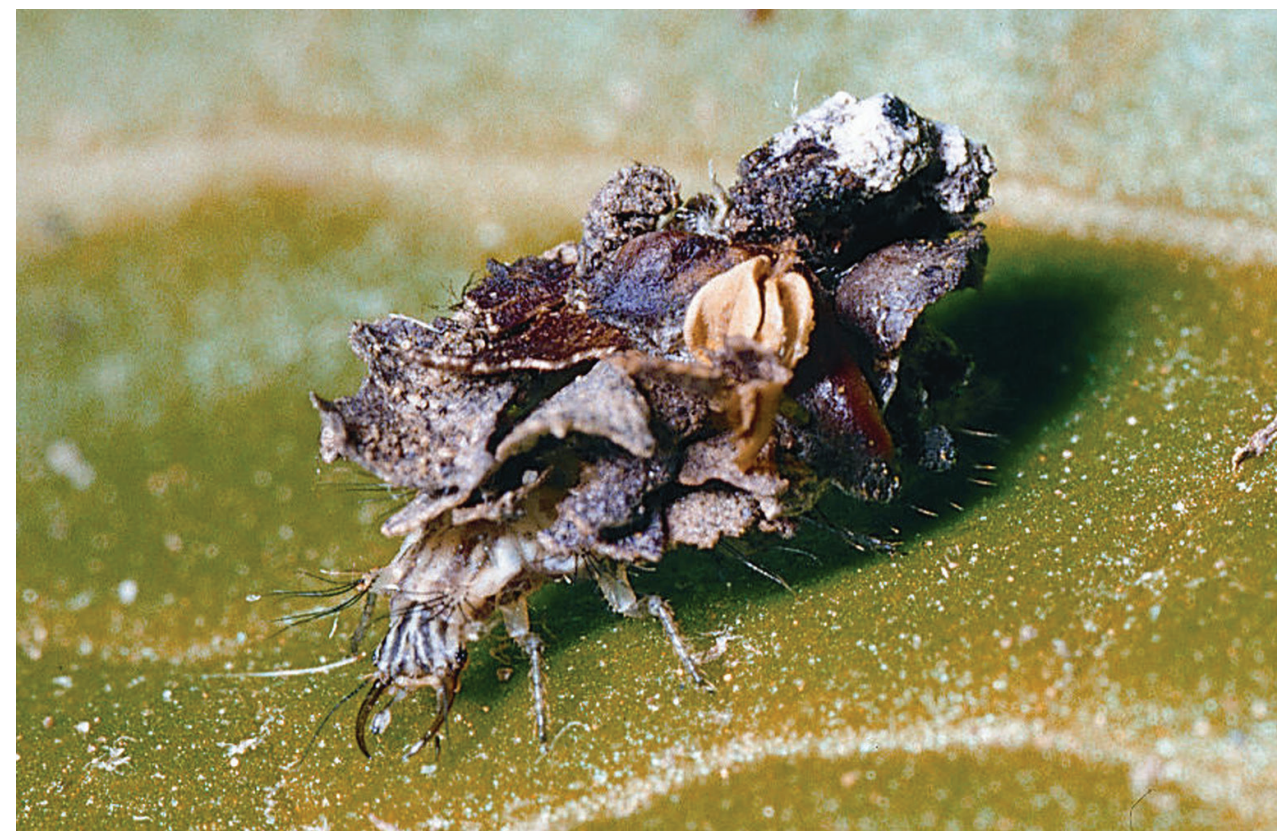

Figure 10. Kymachrysa intacta third instar (darkly marked). Note head markings, debris packet containing woody and dried plant material. (Photo: Stephen A. Marshall).

trees. The larvae are debris-carriers; typically they carry pieces of bark or other woody or plant material that blends with their typical substrate (Fig. 10).

Developmental stages are relatively prolonged, and they are strongly influenced by photoperiod (Tauber et al. 1998). The life cycle appears to be univoltine. Larvae overwinter as diapausing second instars. Short daylengths decelerate development during the first instar, and they induce and maintain hibernal diapause in second instars. Daylength also may be important during the postdiapause developmental period. Under field conditions (Tompkins and Schyler Counties, NY), adults emerge in June, and eggs occur from July through late September or early October. Such a life cycle is unusual, but not unknown, for other chrysopids. For example, free-living second and third instars of Pseudomallada species also overwinter in a photoperiodically induced diapause (Principi and Sgobba 1987, 1993, Canard et al. 1990).

Kymachrysa's generic relationships. With the addition of Kymachrysa, a total of 17 genera of Chrysopini are now known from the New World. Table 2 lists the eleven that are reported from North America, including Mexico, and it provides references to their distributions.

Above, we showed that Kymachrysa adults (males and females) express a number of characteristics that provide strong morphological support for a distinct genus. However, its relationship with other chrysopine genera remains perplexing. In general, the male genital structures resemble those of Ceraeochrysa, whereas the female genitalia (apart from the presence of a praegenitale in Kymachrysa) appear similar to those of 
Table 2. Genera in the tribe Chrysopini reported from North America, including the new genus, Kymachrysa.

Ceraeochrysa Adams, 1982 - New World, largely Neotropical; 15 species in North America (Valencia Luna et al. 2006, Garland and Kevan 2007, Freitas et al. 2009, Tauber and Flint 2010)

Chrysopa Leach in Brewster, 1815 - Holartic; eleven confirmed species in North America (Penny et al. 1997, Garland and Kevan 2007, Valencia Luna et al. 2006)

Chrysoperla Steinmann, 1964 - Worldwide; ten species from North America (Brooks 1994, Valencia Luna et al. 2006, Henry et al. 2012)

Chrysopodes (Neosuarius) Adams \& Penny, 1985 - Neotropical; largely Central and South America; one species from North America (Adams and Penny 1985, Tauber 2003, Valencia Luna et al. 2006, Garland and Kevan 2007)

Eremochrysa Banks, 1903 - Nearctic, West Indies; largely southwestern USA \& northern Mexico: Eremochrysa (Chrysopiella) Banks, 1911, four species; Eremochrysa (Eremochrysa) Banks 1903, thirteen species (Penny et al. 1997, Valencia Luna et al. 2006, Garland and Kevan 2007, Oswald 2013)

Kymachrysa gen. n. - Nearctic (Canada, USA, and montane Mexico), two species

Meleoma Fitch, 1855 - Nearctic, Neotropical, largely USA and Mexico; 28 species (Tauber 1969, Brooks and Barnard 1990, Penny 2006, Garland and Kevan 2007)

Nineta Navás, 1912 - Holarctic; two species from North America (USA, Canada) (Penny et al. 1997,

Garland and Kevan 2007)

Plesiochrysa Adams, 1982 - Neotropical, Oriental, Australasia; -25 species with two from North America (southern USA \& Mexico) (Penny et al. 1997, Valencia Luna et al. 2006)

Pseudomallada Tsukaguchi, 1995 - Holarctic; large genus ( -165 species) with five species from North America (Adams and Garland 1982)

Yumachrysa Banks, 1950 - Western USA, Mexico; four species (Penny et al. 1997, Oswald et al. 2002)

several other genera (e.g., Ungla, Pseudomallada). Finally, its larval morphology is very close to that of Chrysopodes, and its biological traits (larval habitat, overwintering stage, photoperiodically controlled diapause) resemble those of Pseudomallada. Resolution of the dilemma posed by the above mixture of similarities awaits a broadly based phylogenetic analysis of chysopid genera.

\section{Modifications for Brooks and Barnard's (1990) key to adults of chrysopid genera}

In the most recent taxonomic key for chrysopid genera (Brooks and Barnard 1990), both Kymachrysa and Ceraeochrysa males are recovered at couplet 45. However, the two species can be differentiated with the following changes and additions to the couplet:

45 Fore wing narrow (length : breadth $>2.8: 1$ ); anal veins not crassate; radial crossveins (between $\mathrm{R}$ and Rs) usually straight; median plate [= gonarcal bridge] with dorsal horns [= gonocornua] (Brooks and Barnard 1990, fig. 268) ......45A

- $\quad$ Fore wing broad (length : breadth $\leq 2.8: 1$ ); anal veins crassate; radial crossveins (between $\mathrm{R}$ and Rs) usually sinuate; median plate [= gonarcal bridge] without dorsal horns [= gonocornua] (Brooks and Barnard 1990, figs 335,346 ) 
45A Fore wing with veins between gradate veins straight; dorsum of T9+ect invaginated apically, but fused at least basally (male and female); male with ventral apodeme of $\mathrm{S} 8+9$ not elongated, extending anteriorly at most to margin of S8, not beyond; spermatheca cylindrical, with U-shaped or J-shaped bend opening to bursa copulatix.....

Ceraeochrysa Adams

- $\quad$ Fore wing with veins between gradate veins sinuate (wavy); dorsum of T9+ect separate (unfused or divided) dorsally (male and female); male with ventral apodeme of S8+9 elongate, extending anteriorly beyond margin of S8; spermatheca pillbox-shaped, with velum opening to bursa copulatrix via small bursal duct

Kymachrysa gen. $\mathbf{n}$.

\section{Catalog of Kymachrysa species}

\section{Kymachrysa placita (Banks, 1908), comb. n.}

Chrysopa placita Banks, 1908: 259 [MCZ, Lectotype, designated by Tauber and Flint 2010: 61].

Ceraeochrysa placita (Banks). First combination in Ceraeochrysa by Adams (1982: 73). Removed from Ceraeochrysa by Tauber (2003: 484). Combination reinstated by Freitas et al. (2009: 568), but subsequently considered uncertain by Tauber and Flint (2010: 64).

Chrysopodes (Neosuarius) placitus [= placita] (Banks). First combination in Chrysopodes (Neosuarius) by Tauber (2003: 484). Removed from Chrysopodes by Freitas et al. (2009: 568). Generic and subgeneric association with Chrysopodes (Neosuarius) considered uncertain by Tauber (2010: 12).

Chrysopa forreri Navás, 1913-14 [1914]: 97 [Syntype, The Natural History Museum, London (BMNH)]. Junior subjective synonym of Cer. placita by Adams (1982: 73). Recognized as a junior subjective synonym of Ceraeochrysa intacta (Navás) by Tauber and Flint (2010: 62).

Chrysopa intacta Navás, 1912: 199 [Neotype, Canadian National Collection, Ottawa, (CNC), designated by Garland 1985: 138]. Junior subjective synonym of Cer. placita by Garland (1985: 137). Recognized as a valid species, with uncertain generic assignment by Tauber and Flint (2010: 62).

Species specific characters. The species was most recently re-described by Freitas et al. (2009: 568). Externally, it is recognized by its characteristic broad, dark brown facial markings (Fig. 4) and broadly cleft tarsal claws (Fig. 8C). The distinctive male features include: microtholi absent (Fig. 8A); ventral apodeme of S8+9 convex, with smooth curve; gonocornua broad, touching each other mesally (Fig. 6). Female character states include: spermathecal invagination small $\left(<1 / 4^{\text {th }}\right.$ the width of the spermatheca), shallow $(<1 / 2$ the depth of the spermatheca); basal section of spermathecal duct smooth, without hairiness (Fig. 3). The larvae and biology are unknown. 
Geographic distribution. We have seen specimens or reliable reports only from the USA (AZ: Chafee, Cochise Co.; CO: Clear Creek, Larimer, Jefferson Co.; NM: Cibola Co.; UT: Uintah Co.; WY: Albany Co.).

\section{Kymachrysa intacta (Navás, 1912), comb. n.}

Chrysopa intacta Navás, 1912: 199 [Original syntype reported to have been retained in Navás collection, probably destroyed; Neotype, CNC; designated by Garland (1985: 137)]. Junior subjective synonym of Cer. placita by Garland (1985: 137).

Ceraeochrysa intacta (Navás), genus incertae sedis. Recognized as a valid species, with uncertain generic assignment by Tauber and Flint (2010: 62).

Chrysopa forreri Navás, 1913-14 [1914]: 97 [Syntype, BMNH]. Junior subjective synonym of Cer. intacta by Tauber and Flint (2010: 61).

Ceraeochrysa chiricahuae Freitas \& Penny, in Freitas et al. 2009: 594 [Holotype, CAS]. Junior subjective synonym of Cer. intacta by Tauber and Flint (2010: 61).

Remarks. In addition to the citations listed above that refer to synonymies and nomenclatural changes, Garland and Kevan (2007: 59) provide a list of references containing information on $K$. intacta under the name placitalplacitus [as Chrysopa, Ceraeochrysa, Chrysopodes (Neosuarius), Oviedus]; other references include Tauber and de León (2001, as Ceraeochrysa placita); Tauber (2010: 12, as Chrysopodes placitus); Tauber et al. 2014: Suppl, Material, as Ceraeochrysa placita, incertae sedis).

Species specific characters. This species was re-described by Tauber et al. (1998, 2000, as Ceraeochrysa placita), Tauber (2003, as Chrysopodes placita), and Freitas et al. (2009: 594, as Ceraeochrysa chiricahuae). Adults are recognized by their slender, red markings on the head and thorax (Fig. 5) and narrowly cleft tarsal claws (Fig. 8D; also see Garland 1982, fig. 74k), as well as their distinctive male and female genitalia. The male features include: microtholi sometimes present (see below); ventral apodeme of S8+9 irregular, with several small curves and a mesal bend; gonocornua narrow, separated from each other basally (Fig. 7). In the female, the spermathecal invagination is large $\left(\sim 1 / 3^{\text {rd }}\right.$ the width of the spermatheca) and relatively deep $(>1 / 2$ the depth of the spermatheca), and the basal section of the spermathecal duct is hairy (Fig. 3).

Specimens of $K$. intacta from eastern and western North America appear very similar to each other, but we found some geographic variation of note. First, the male abdominal sternites are densely covered with microtholi on our specimens from California (Alameda, Kern, and Sierra Counties) (Fig. 8B). In contrast, microtholi are very sparse or absent on specimens from Utah (Wasatch County) and Colorado (Larimer County), and absent from specimens from New Hampshire (Belknap County) and New York (Tompkins and Schuyler Counties) (as in Fig. 8 for K. placita; also see Garland 1982). Second, larvae (second and third instars) from the west were reported to have somewhat denser abdominal setation than those of the east (Tauber et al. 1998). And, finally, the length of the stalk that supports the egg is considerably longer in east- 


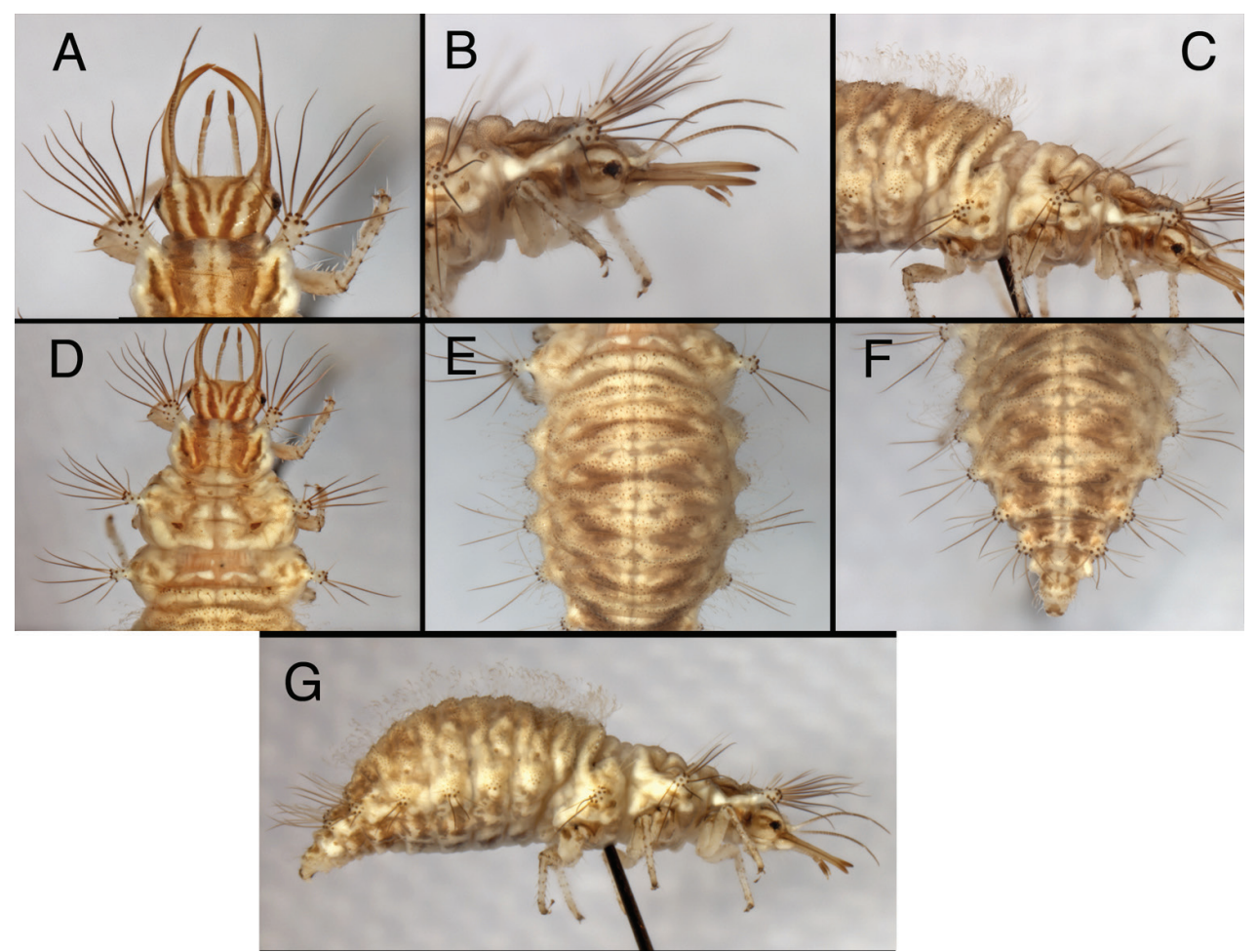

Figure I I. Kymachrysa intacta third instar. A Head (dorsal) B Head (lateral) C Thorax (lateral) D Thorax (dorsal) E Abdominal segments 1-4 (dorsal) F Abdominal segments 4-10 (dorsal) G Body (lateral). All New York, TRC.

ern than in western populations (eastern: $2.1-3.3 \mathrm{~mm}$; western: $1.4-2.3 \mathrm{~mm}$ ) (Tauber et al. 1998). Given the potential role of microtholi in courtship, we suspect that the above variation may indicate at least some reproductive isolation between eastern and western populations.

The larvae of $K$. intacta have been described (Tauber et al. 1998, 2000, Tauber 2003); for images, see Fig. 11 here. Below are some modifications and corrections to the earlier descriptions:

(a) Semaphorant A (L1): Thorax as figured by Tauber et al. (1998, Fig. 8), with following differences: Mesothorax with Sc1, Sc2 present anteriorly on folds as in Chrysopodes (see Tauber 2003, fig. 10); Sc3 present, posteromesal to lateral tubercles, with one medium-length and sometimes one small associated setae; $S 1$ small or absent; S2 medium-length, mesal to Sc3, smooth to finely sabulose. Metathorax with Sc3 present, mesal to lateral tubercle, with one or two small associated setae (S1Sc3, S2Sc3); several very small setae anterior to Sc3, probably associated with a very pale Sc2.

(b) Semaphorant B (L3, L2): Prothorax with S1 and S1Sc1 smooth to very finely sabulose, not thorny. Mesothorax with Sc2 present mesal to lateral tubercles, with two small 
associated setae (S1Sc2, S2Sc2); S1 present, small; S2 small or absent; S3 of mediumlength, slightly granular; S4 small, smooth; but S1Sc3 small, S2Sc3 slightly longer. Metathorax with posterior row of setae (R1) arising from large chalazae.

Geographic distribution. This species occurs broadly throughout North America. We have seen specimens or reliable records from: Canada (ON, QC; see Garland 1984); United States (AZ, CA, CO, MN, MO, NC, NH, NM, NV, NY, OR, TN, TX, UT, WS, WV, WY; see Penny et al. 1997); and Mexico (Dgo., D.F., Mich.; see Valencia Luna et al. 2006).

Kymachrysa placita and K. intacta were collected sympatrically in Rustler Park, Cochise Co., AZ, 6-Aug-1991, by R. \& J. Robertson (CAS).

\section{Acknowledgements}

Special thanks go to Maurice J. Tauber (Cornell University, MJT) for his careful reading of the manuscript and constructive suggestions, John Rawlins (Carnegie Museum of Natural History) and Oliver S. Flint (Smithsonian Institution) for their earlier comments and suggestions, and Stephen A. Marshall (University of Guelph) for use of his photo (Fig 10). We thank N. D. Penny (CAS), C. Barr and P. T. Oboyski (EMEC), S. P. Cover \& P. Perkins (MCZ), C. Darling and B. Hubley (ROM), O. Flint (USNM), D. Goodger (BMNH), B. Kondartieff (CPG), J. K. Liebherr (CUIC), O. Lonsdale (CNC), J. E. Rawlins (CMNH), and M. Wall (SDNHM) for providing access to types and specimens in their care. The "Lacewing Digital Library" website, developed by J. D. Oswald (Texas A \& M University, College Station), was very useful to this study. CAT's work has benefitted from funding by the National Science Foundation (DEB 0542373, with MJT), USDA/NRI Competitive Grants Programs (9802447, with MJT), and Cornell University.

\section{References}

Adams PA (1982) Ceraeochrysa, a new genus of Chrysopinae (Neuroptera) (Studies in New World Chrysopidae, Part II). Neuroptera International 2: 69-75.

Adams PA, Garland JA (1982) A review of the genus Mallada in the United States and Canada, with a new species (Neuroptera: Chrysopidae). Psyche 89: 239-248. doi: $10.1155 / 1982 / 17827$

Adams PA, Penny ND (1985) [1987] Neuroptera of the Amazon Basin. Part 11a. Introduction and Chrysopini. Acta Amazonica 15: 413-479.

Banks N (1908) Neuropteroid insects - notes and descriptions. Transactions of the American Entomological Society 34: 255-267.

Brooks SJ (1994) A taxonomic review of the common green lacewing genus Chrysoperla (Neuroptera: Chrysopidae). Bulletin of the Natural History Museum, Entomology 63: 137-210. 
Brooks SJ, Barnard PC (1990) The green lacewings of the world: a generic review (Neuroptera: Chrysopidae). Bulletin of the British Museum of Natural History, Entomology 59: 117-286. Canard M, Grimal A, Hatté M (1990) Larval diapause in the Mediterranean green lacewing Mallada picteti (MacLachlan) (Neuroptera: Chrysopidae): induction by photoperiod, sensitive and responsive stages. Bollettino dell'Istituto di Entomologia "Guido Grandi" della Università degli studi di Bologna 44: 65-74.

Freitas S de, Penny ND (2001) The green lacewings (Neuroptera: Chrysopidae) of Brazilian agro-ecosystems. Proceedings of the California Academy of Sciences 52: 245-395.

Freitas S de, Penny ND, Adams PA (2009) A revision of the New World genus Ceraeochrysa (Neuroptera: Chrysopidae). Proceedings of the California Academy of Sciences 60: 503-610. Garland JA (1982) The taxonomy of the Chrysopidae of Canada and Alaska (Insecta: Neuroptera). PhD dissertation. McGill University, Ste Anne-de-Bellevue, Québec, 157 pp.

Garland JA (1984) Catalogue of Chrysopidae of Canada and Alaska. Neuroptera International 3: 93-94. [Corrigenda 3: 149]

Garland JA (1985) Une nouvelle synonymie de Ceraeochrysa placita (Banks), espece NordAmericaine, avec designation d'un neotype (Planipennia, Chrysopidae). Neuroptera International 3: 137-138.

Garland JA, Kevan DK McE (2007) Chrysopidae of Canada and Alaska (Insecta, Neuroptera): revised checklist, new and noteworthy records, and geo-referenced localities. Zootaxa 1486: 1-84. [Erratum: 1507: 68]

Henry CS, Brooks SJ, Duelli P, Johnson JB, Wells MM, Mochizuki A (2012) Parallel evolution in courtship songs of North American and European green lacewings (Neuroptera: Chrysopidae). Biological Journal of the Linnean Society 105: 776-796. doi: 10.1111/j.10958312.2011.01845.x

Navás L (1912) Neurópteros nuevos de América [unnumbered part 1]. Brotéria (Zoológica) 10: 194-202.

Navás L (1913-1914) [1914] Les Chrysopides (Ins. Névr.) du Musée de Londres [Ib]. Annales de la Société Scientifique de Bruxelles 38(2): 73-114.

Oswald JD (2013) Neuropteria Species of the World. Version 3.0. http://lacewing.tamu.edu/ Species-Catalogue/ [accessed on 17 May 2014]

Oswald JD, Contreras-Ramos A, Penny ND (2002) Neuroptera (Neuropterida). In: Bousquets JL, Morrone JJ (Eds) Biodiversidad, Taxonomía y Biogeografía de Artrópodos de México: hacia una síntesis de su conocimiento, Vol. 3. Universidad Nacional Autónoma de México, Distrito Federal, Mexico, 559-581.

Penny ND (2006) Two new species of Meleoma (Neuroptera: Chrysopidae) from western North America, with a revised key to species. Annals of the Entomological Society of America 99: 58-63. doi: 10.1603/0013-8746(2006)099[0058:TNSOMN]2.0.CO;2

Penny ND, Adams PA, Stange LA (1997) Species catalog of the Neuroptera, Megaloptera, and Raphidioptera of America North of Mexico. Proceedings of the California Academy of Sciences 50: 39-114.

Penny ND, Tauber CA, de León T (2000) A new species of Chrysopa from western North America with a key to North American species (Neuroptera: Chrysopidae). Annals of the Ento- 
mological Society of America 93: 776-784. doi: 10.1603/0013-8746(2000)093[0776:ANSOCF]2.0.CO;2

Penny ND, Adams PA, Stange LA (1997) Species catalog of the Neuroptera, Megaloptera, and Raphidioptera of America North of Mexico. Proceedings of the California Academy of Sciences 50: 39-114.

Principi MM, Sgobba D (1987) La diapausa larvale in Mallada (=Anisochrysa) flavifrons (Brauer) (Neuroptera Chrysopidae): cicli fotoperiodici responsabili dell'induzione, sviluppo di diapausa e attivazione, accrescimento ponderale dello stadio con diapausa. Bollettino dell'Istituto di Entomologia "Guido Grandi" della Università degli studi di Bologna 41: 209-231.

Principi MM, Sgobba D (1993) La diapausa larvale in Mallada clathratus (Schneider) (Neuroptera Chrysopidae). Bollettino dell'Istituto di Entomologia "Guido Grandi" della Università degli studi di Bologna 48: 75-91.

Silva PS, Tauber CA, Albuquerque GS, Tauber MJ (2013) Larvae of five horticulturally important species of Chrysopodes (Neuroptera, Chrysopidae): shared generic features, descriptions and keys. ZooKeys 262: 39-92. doi: 10.3897/zookeys.262.4119

Sosa F, Freitas S de (2010) New neotropical species of Ceraeochrysa Adams (Neuroptera: Chrysopidae). Zootaxa 2562: 57-65.

Sosa F, Freitas S de (2011) A new synonym, a new male description and new geographical records for three Ceraeochrysa species (Neuroptera: Chrysopidae). Zootaxa 2913: 47-58.

Tauber CA (1969) Taxonomy and biology of the lacewing genus Meleoma (Neuroptera: Chrysopidae). University of California Publications in Entomology 58: 1-94.

Tauber CA (1974) Systematics of North American chrysopid larvae: Chrysopa carnea group (Neuroptera). Canadian Entomologist 106: 1133-1153. doi: 10.4039/Ent1061133-11

Tauber CA (1975) Larval characteristics and taxonomic position of the lacewing genus Suarius. Annals of the Entomological Society of America 68: 695-700.

Tauber CA (2003) Generic characteristics of Chrysopodes (Neuroptera: Chrysopidae), with new larval descriptions and a review of species from the United States and Canada. Annals of the Entomological Society of America 96: 472-490. doi: 10.1603/0013-8746(2003)096[0472:GC OCNC]2.0.CO;2

Tauber CA (2010) Revision of Neosuarius, a subgenus of Chrysopodes (Neuroptera: Chrysopidae. ZooKeys 44: 1-104. doi: 10.3897/zookeys.44.387

Tauber CA, Flint OS Jr (2010) Resolution of some taxonomic and nomenclatural issues in a recent revision of Ceraeochrysa (Neuroptera: Chrysopidae). Zootaxa 2565: 55-67. [Errata: 2572: 68]

Tauber CA, de León T (2001) Systematics of green lacewings (Neuroptera: Chrysopidae): larvae of Ceraeochrysa from Mexico. Annals of the Entomological Society of America 94: 197-209. doi: 10.1603/0013-8746(2001)094[0197:SOGLNC]2.0.CO;2

Tauber CA, de León T, López-Arroyo JI, Tauber MJ (1998) Ceraeochrysa placita (Neuroptera: Chrysopidae): generic characteristics of larvae, larval descriptions, and life cycle. Annals of the Entomological Society of America 91: 608-618.

Tauber CA, de León T, Penny ND, Tauber MJ (2000) The genus Ceraeochrysa (Neuroptera: Chrysopidae) of America North of Mexico: larvae, adults, and compara- 
tive biology. Annals of the Entomological Society of America 93: 1195-1221. doi: 10.1603/0013-8746(2000)093[1195:TGCNCO]2.0.CO;2

Tauber CA, Albuquerque GS, Tauber MJ (2012) Three new Brazilian species of Chrysopodes (Neuroptera: Chrysopidae). Annals of the Entomological Society of America 105: 638-663. doi: 10.1603/AN12028

Tauber CA, Tauber MJ, Albuquerque GS (2014) Debris-carrying in larval Chrysopidae: Unraveling its evolutionary history. Annals of the Entomological Society of America 107: 295-314. doi: 10.1603/AN13163

Tjeder B (1966) Neuroptera-Planipennia. The Lace-wings of Southern Africa. 5. Family Chrysopidae. In: Hanström B, Brinck P, Rudebec G (Eds) South African Animal Life. Vol. 12. Swedish Natural Science Research Council, Stockholm, 228-534.

Valencia Luna LA, Romero Nápoles J, Valdez Carrasco J, Carrillo Sánchez JL, López Martínez V (2006) Taxonomia y registros de Chrysopidae (Insecta: Neuroptera) en el Estado de Morelos, México [=Taxonomy and records of Chrysopidae (Insecta: Neuroptera) in the state of Morelos, Mexico]. Acta Zoológica Mexicana (NS) 22: 17-61. 